\title{
Water injection for gasoline engines: Potentials, challenges, and solutions
}

International J of Engine Research 2016, Vol. 17(I) 86-96 (c) IMechE 2015 Reprints and permissions: sagepub.co.uk/journalsPermissions.nav DOI: $10.1177 / 1468087415599867$ jer.sagepub.com \&SAGE

\author{
Fabian Hoppe', Matthias Thewes ${ }^{2}$, Henning Baumgarten ${ }^{2}$ \\ and Jürgen Dohmen ${ }^{2}$
}

\begin{abstract}
Further significant $\mathrm{CO}_{2}$ emission reduction beyond 2020 is mandatory in the United States and might also become mandatory in Europe, depending on the passenger car $\mathrm{CO}_{2}$ legislation, which is to be enacted. Hybrid and plug-in hybrid vehicles might account for a big portion of these $\mathrm{CO}_{2}$ reductions as a consequence of the favourable current legislative treatment which does not associate $\mathrm{CO}_{2}$ emissions from electric power generation with vehicle $\mathrm{CO}_{2}$ emissions. Nevertheless, these powertrains benefit from a highly efficient combustion engine. Exhaust heat recovery poses new synergetic possibilities for technologies to mitigate knock like cooled external exhaust gas recirculation and condensed water injection. The condensed water injection concept, which is proposed in this article, demonstrates a potential for efficiency increase of $3.3 \%-3.8 \%$ in the region of the minimum specific fuel consumption on a stoichiometric combustion concept with Miller cycle and cooled external exhaust gas recirculation. Further improvement of the efficiency of up to $16 \%$ is possible at full-load operation. If water injection is used in addition to homogeneous lean combustion, an efficiency gain of $4.5 \%$ in the region of the minimum specific fuel consumption is achieved.
\end{abstract}

\section{Keywords}

Spark ignition engine, water injection, direct injection, knock reduction, condensate, miller cycle, external exhaust gas recirculation

Date received: 12 May 20I5; accepted: 10 July 2015

\section{Introduction}

One major challenge for today's society is the sustainable satisfaction of its energy demand. Currently, the entire transportation sector uses primarily fossil fuels. Despite the recent improvements in electrical vehicles, a total independence of internal combustion engines cannot be foreseen for the upcoming years. Furthermore, it is not very likely that sufficient amounts of bio-fuels from large-scale productions will be available in the near future. Consequently, high effort is required for the improvement of conventional combustion engines, which are fuelled with crude oil-derived fuels to fulfil the mandatory $\mathrm{CO}_{2}$ emission reduction beyond 2020 in the United States. This reduction might also become mandatory in Europe, depending on the passenger car $\mathrm{CO}_{2}$ legislation, which is to be enacted. ${ }^{1-4}$

Exhaust heat recovery is one potential technology that might become even more attractive in the future against the background of the worldwide harmonized light vehicles test procedure (WLTP). Besides, exhaust heat recovery already provides cooled exhaust gases for exhaust gas recirculation (EGR) applications. Principally, low-pressure EGR can be applied in the entire engine map, if sufficient cooling capacity can be provided by the vehicle cooling system. In such a case, the increase in the geometric compression ratio becomes possible as well. Besides the improvement of the thermal efficiency, which is due to the increased compression ratio and/or reduced knock tendencies, the thermodynamic properties of the fluid also improve, while the wall heat losses can be reduced. ${ }^{5-8}$

In this respect, potential synergies that could be enabled by exhaust heat recovery have been sought in order to improve the efficiency of the gasoline combustion even further. Thus, the condensate injection concept was developed. ${ }^{9}$ Further heat rejection in addition

\footnotetext{
'Institute for Combustion Engines, RWTH Aachen University, Aachen, Germany

${ }^{2} \mathrm{FEV} \mathrm{GmbH}$, Aachen, Germany
}

\section{Corresponding author:}

Fabian Hoppe, Institute for Combustion Engines, RWTH Aachen University, Forckenbeckstr. 4, 52074 Aachen, Germany.

Email: hoppe@vka.rwth-aachen.de 
to technologies such as heat to cool, ${ }^{10}$ thermoelectric generator, ${ }^{11,12}$ and Rankine process ${ }^{13}$ would enable to cool down the exhaust gas below the dew point. In Figure 1, the result of a worst case assumption of the calculation of the dew point is depicted. Depending on the pressure level and the relative air/fuel ratio, a temperature of approximately $40^{\circ} \mathrm{C}-56^{\circ} \mathrm{C}$ would need to be achieved to fall below the dew point when the engine is operated in dry ambient air. This condensed exhaust gas is fed back into the engine. In a possible extension of this concept, the condensed water from the air conditioning system can be added to a buffer tank out of which the condensate is extracted and fed into the engine. At the same time, the efficiency of the exhaust heat recovery via a Rankine process can be improved by lowering the lower temperature of the heat transfer.

\section{Direct condensate injection concept}

Based on the results of prior investigations presented by Thewes et al., ${ }^{9}$ the initial concept was extended by two aspects. Instead of port injection, direct injection (DI) was considered for the condensate as well as for the gasoline injection. Moreover, the condensation concept was changed to utilizing the condensate of the entire exhaust gas and not only the EGR condensate. At the dew point of approximately $40{ }^{\circ} \mathrm{C}-56^{\circ} \mathrm{C}$, the exhaust gas leaving the tailpipe has a relative humidity of $100 \%$. The mass of contained water is formed entirely during the combustion of the fuel. Additional injected water will be condensed. Thus, this operation principle allows the entire injected condensate to be recycled.

The charge cooling effect of the evaporation of the injected water mass is used to reduce the cylinder temperature and pressure. This allows for more efficient spark timings, due to reduced knock sensitivity. ${ }^{14-23}$ Water is preferred as additional injected fluid due to its high enthalpy of vaporization $\left(\Delta \mathrm{h}_{\mathrm{v} \text {,water }}\right)$. Its value of $2430 \mathrm{~kJ} / \mathrm{kg}^{24}$ is higher than the enthalpies of vaporization of RON95 E5 gasoline $\left(\sim 397 \mathrm{~kJ} / \mathrm{kg}^{25}\right)$ and ethanol $\left(952 \mathrm{~kJ} / \mathrm{kg}^{24}\right)$ by factors of more than 6 and 2.5 , respectively. At the same time, water features a higher specific heat capacity $\left(c_{p}\right)$ than air. Therefore, an additional cooling effect during compression and combustion takes place when water is added to the cylinder charge. A theoretical assessment according to the fuel-air cycle $^{26}$ was conducted to evaluate the influence of the heat capacity and the enthalpy of vaporization of water on the mixture temperature when water injection is applied. The values for the calculations are taken from references Yaws, ${ }^{24}$ Scott $^{27}$ Scott, $^{28}$ and Chase. ${ }^{29}$ Isooctane is considered as a surrogate for gasoline. In Figure 2, three different cases are displayed:

1. Reference cycle without water injection.

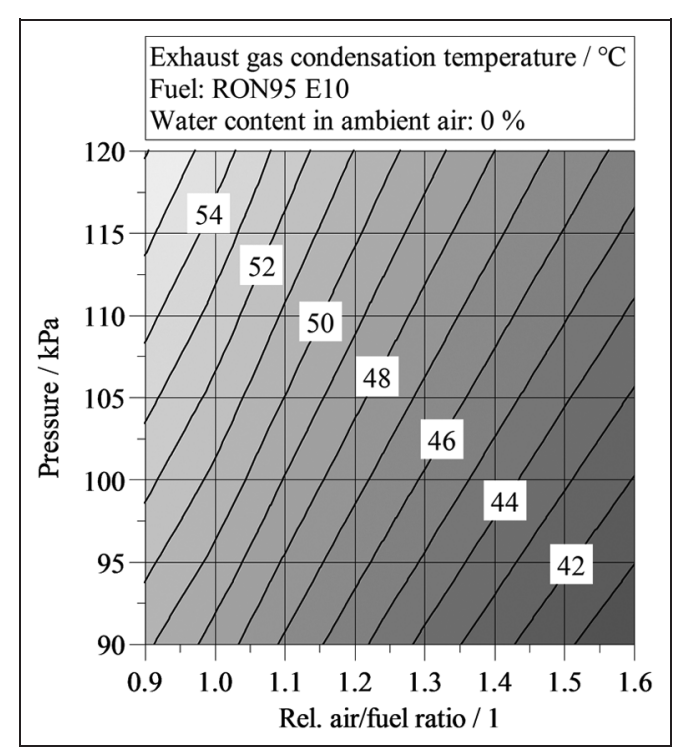

Figure I. Dew point of gasoline exhaust gas in dependency of pressure and relative air/fuel ratio.

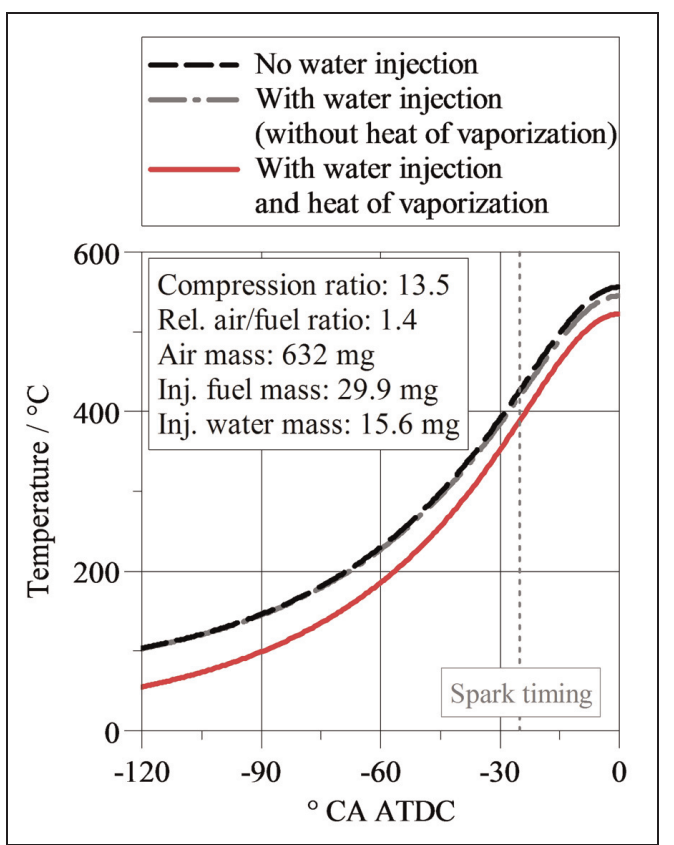

Figure 2. Influence of the specific heat and the enthalpy of vaporization on the mixture temperature in the fuel-air cycle.

2. Cycle where water injection is applied but is assumed to be injected in gaseous phase to avoid the influence of the enthalpy of vaporization.

3. Cycle with water injection where the additional cooling due to evaporation is considered.

Isooctane and air are assumed to be premixed at $-180^{\circ}$ crank angle (CA) after top dead centre (ATDC) when water is injected for $30^{\circ} \mathrm{CA}$ with instantaneous evaporation. The injected water mass corresponds to a water/fuel ratio of $52 \%$. 
For the case without the evaporative cooling, an increasing influence of the heat capacity of water is visible with higher mixture temperatures, whereas at the beginning of the compression no significant difference is visible. This is due to the fact that the mixture without water has only slightly lower specific heat capacity as the injected water mass is rather small compared to the air mass. However, due to the accumulation of these slight temperature differences in every step, an increased influence at the end of the compression is visible. An additional reason for that can be seen in the higher temperature dependency of the heat capacity of water compared to that of air. This leads to a reduction in mixture temperature of approximately $7{ }^{\circ} \mathrm{C}$ at spark timing. When the evaporation of water is added, a total temperature decrease of approximately $34{ }^{\circ} \mathrm{C}$ is present and thus dominated by the evaporative cooling. For stoichiometric mixtures with and without EGR, the influence of the heat capacity of water is even less. Therefore, it can be stated that the charge cooling effect of water injection is almost entirely due to evaporation.

It can be assumed that the vaporization of fuel and the mixture formation are negatively affected by the evaporation of the injected water as the temperature reduction leads to a lower vapour pressure. Apart from vaporization, mixture formation is also affected by the spray breakup. It can be separated into the primary and the secondary breakup. However, according to investigations of Ohnesorge, the primary breakup can be classified by the Reynolds (Re) and the Ohnesorge (Oh) number. ${ }^{30,31}$ The Re number, see equation (1), can be interpreted as the quotient of the inertia and the viscous forces. The $\mathrm{Oh}$ number, see equation (3), is defined as the quotient of the square root of the Weber (We) number, see equation (2), and the Re number. Consequently, the $\mathrm{Oh}$ number can be construed as the viscous forces divided by the square root of both the inertia forces and the surface tension. The nomenclature of the symbols used in equations (1) - (3) can be found in Appendix 1.

$$
\begin{aligned}
& \mathrm{Re}=\frac{\rho^{*} v^{*} \mathrm{~d}}{\eta} \\
& \mathrm{We}=\frac{\rho^{*} v^{2 *} \mathrm{~d}}{\sigma} \\
& \mathrm{Oh}=\frac{\sqrt{\mathrm{We}}}{\operatorname{Re}}=\frac{\eta}{\sqrt{\mathrm{d}^{*} \rho^{*} \sigma}}
\end{aligned}
$$

As a modification of a Reynolds-Ohnesorge diagram presented by Thewes and colleagues, ${ }^{25,32}$ Figure 3 shows a comparison between water at different injection pressures and isooctane at $20 \mathrm{MPa}$ injection pressure. The latter is considered as a surrogate for gasoline again. Reynolds $(\mathrm{Re})$ and Ohnesorge $(\mathrm{Oh})$ numbers are calculated assuming a fuel temperature of $25{ }^{\circ} \mathrm{C}$. The nozzle exit velocity of the six-hole solenoid injector used within this study is derived via the Bernoulli equation, according to the specific properties and pressure

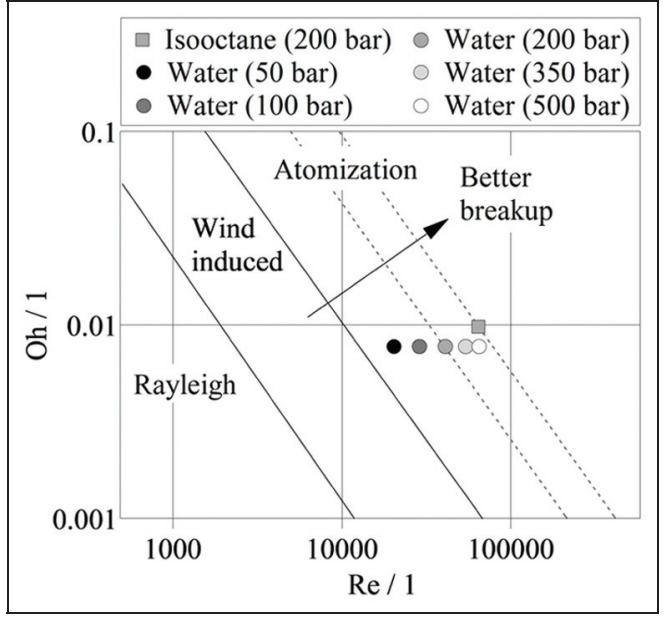

Figure 3. Ohnesorge-Reynolds diagram with expected primary breakup regions for isooctane and water at various injection pressures.

Table I. Thermophysical properties of isooctane and water. $^{24,33,34}$

\begin{tabular}{lll}
\hline & Isooctane & Water \\
\hline Density $\left(25^{\circ} \mathrm{C}\right)\left(\mathrm{kg} / \mathrm{m}^{3}\right)$ & 690 & 999 \\
Viscosity $\left(25^{\circ} \mathrm{C}\right)(\mathrm{mPa} \mathrm{s})$ & 0.467 & 0.882 \\
Surface tension $\left(25^{\circ} \mathrm{C}\right)(\mathrm{mN} / \mathrm{m})$ & 18.32 & 72.71 \\
Vapour pressure $\left(20^{\circ} \mathrm{C}\right)(\mathrm{kPa})$ & 5.3 & 2.339 \\
\hline
\end{tabular}

of the liquid. Table 1 lists the properties, which were used for the calculation of the characteristic numbers of the liquids. Compared to isooctane, the factor $\sim 2$ higher viscosity of water overcompensates the higher density of water, resulting in a lower Re number. At the same time, the higher viscosity of water is overcompensated by $\sim$ factor 4 lower surface tension of isooctane in combination with the lower density, leading to a lower Oh number in the case of water. Due to the combination of the lower Re and Oh number, a poorer atomization can be expected for water compared to isooctane, also indicated by the dotted lines in Figure 3. By changing the injection pressure, the primary breakup can be influenced. Whereas an increase in the injection pressures from 5 to $10 \mathrm{MPa}$ leads to a significantly better breakup, only minor improvements of the primary breakup can be found for injection pressures above $20 \mathrm{MPa}$. Even for an assumed maximum injection pressure of $50 \mathrm{MPa}$, the primary breakup of water still has to be ranked worse than that of isooctane at an injection pressure of $20 \mathrm{MPa}$.

In addition to the poorer atomization, a worse evaporation compared to gasoline can be expected, due to the lower vapour pressure. Possible issues that might occur due to the combined injection of fuel and water are increased liner impingement and spray interaction of the fuel and water injection. 
Table 2. Hardware specifications of spark-ignited singlecylinder research engine.

\begin{tabular}{lll}
\hline Displacement & $\mathrm{cm}^{3}$ & 364 \\
Bore & $\mathrm{mm}$ & 75 \\
Stroke & $\mathrm{mm}$ & 82.5 \\
Stroke/bore & $\mathrm{I}$ & $\mathrm{I}$ \\
Compression ratio & $\mathrm{I}$ & 13.5 \\
Valves per cylinder & $\mathrm{MPa}$ & 4 \\
Maximum fuel pressure & $\mathrm{MPa}$ & 20 \\
Maximum water pressure & $\mathrm{MPa}$ & 20 \\
Maximum peak firing pressure & ${ }^{\circ}$ CA & 17 \\
Intake valve event length (I mm) & ${ }^{\circ}$ CA ATDC & 230 \\
Intake valve closing (I mm) & ${ }^{\circ}$ CA BTDC & 240 \\
Start of injection (fuel) & & 300 \\
\hline
\end{tabular}

CA: crank angle; ATDC: after top dead centre; BTDC: before top dead centre.

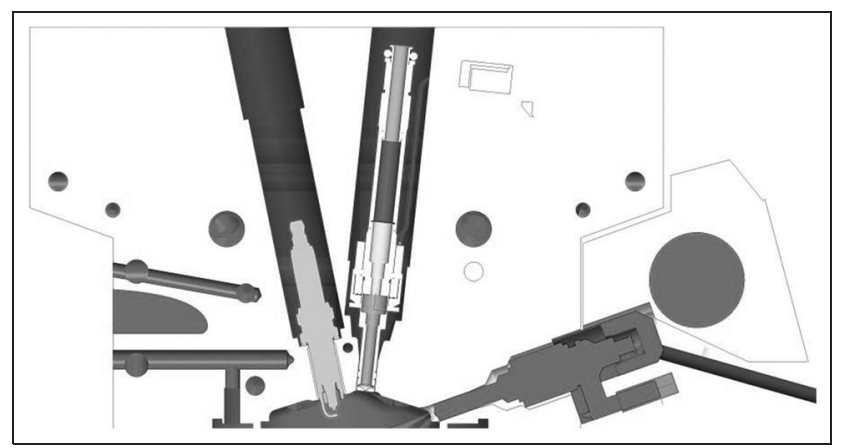

Figure 4. Cylinder head with dual direct injection arrangement.

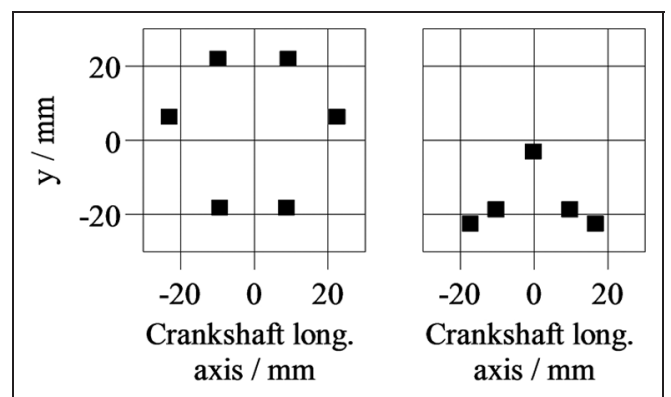

Figure 5. Spray targeting in $35 \mathrm{~mm}$ distance to the injector tip.

\section{Engine specification}

Combustion system investigations regarding the potential benefits of this concept were carried out on a homogeneously operated DI spark-ignited single-cylinder research engine, as already described in previous publications. $^{25,32,35}$

The engine features symmetrical high tumble intake ports and dual hydraulic cam phasing. For this study, the engine was equipped with a Miller cycle intake camshaft, cooled external EGR and a piston enabling a compression ratio of 13.5. More technical data can be derived from Table 2. The central DI injector and the spark plug are placed in central cross position in the combustion chamber roof, which means that the spark plug is installed between the exhaust valves, while the injector is installed between the intake valves, as depicted in the sectional view of the cylinder head in Figure 4. The injector has an inclination of $6^{\circ}$ and the spark plug of $11.5^{\circ}$. The side injector is installed below the intake port at an installation angle of $19.5^{\circ}$. Both the central and the side injectors are solenoid actuated. The central injector features a six-hole spray targeting, which was found to be optimal for the engine in terms of mixture homogenization, oil dilution behaviour, and pre-ignition probability. The side injector features a five-hole spray targeting (see Figure 5). Two volume flow-controlled $20 \mathrm{MPa}$ high-pressure fuel pumps are used to pressurize the fuel and water.

\section{Test bench setup and instrumentation}

For the thermodynamic measurements, the cylinder pressure is measured with two Kistler A6043 A100 pressure transducers, which are flush-mounted in the combustion chamber roof between each intake and exhaust valve seat ring. Sampling is performed via Kistler 5011 charge amplifiers and an FEV Combustion Analysis System (FEVIS) in a resolution of $0.1^{\circ} \mathrm{CA}$. Dynamic intake and exhaust gas pressures are measured with Kistler 4045 A5 pressure transducers and sampled in $1^{\circ} \mathrm{CA}$ resolution. In total, 200 consecutive cycles are measured. The measurements of static pressures and temperatures are performed with conventional pressure transducers and thermocouples during an averaging interval of $30 \mathrm{~s}$. Oil and water conditioning systems allow steady-state operation. The intake air is conditioned to $25^{\circ} \mathrm{C}$ downstream of the electronically controlled throttle flap. The pressure upstream of the throttle flap and in the exhaust manifold is controlled to $101.3 \mathrm{kPa}$ during throttled operation. For charged operation, the pressure in the exhaust system is set up to $3 \mathrm{kPa}$ above the pressure in the intake manifold in order to have sufficient pressure drop for the cooled external EGR. The engine is coupled to an eddy-current brake and an electric dynamometer to maintain the desired engine speed with an accuracy of $\pm 11 / \mathrm{min}$, regardless of the engine load. The intake air mass flow is measured with an ultrasonic air mass meter. Fuel and water consumption are measured via Coriolis-type mass flow sensors. The gaseous exhaust gas composition is determined from a partial mass flow of exhaust gases, which are sampled $60 \mathrm{~cm}$ downstream of the cylinder head flange. The exhaust gas sample is fed to the following emission analysers via a transfer line heated to $193{ }^{\circ} \mathrm{C}$ :

\begin{tabular}{ll}
\hline $\mathrm{HC}$ & Flame ionization detector (Rosemount NGA 2000) \\
$\mathrm{O}_{2}$ & Paramagnetic oxygen analyser (Rosemount NGA 2000) \\
$\mathrm{CO}$ & Infrared gas analyser (Rosemount NGA 2000) \\
$\mathrm{CO}_{2}$ & Infrared gas analyser (Rosemount NGA 2000) \\
$\mathrm{NO}_{\times}$ & Chemiluminescence analyser (Eco Physics 700 EL ht) \\
$\mathrm{PM}$ & Smoke meter (AVL 4I5s) \\
\hline
\end{tabular}




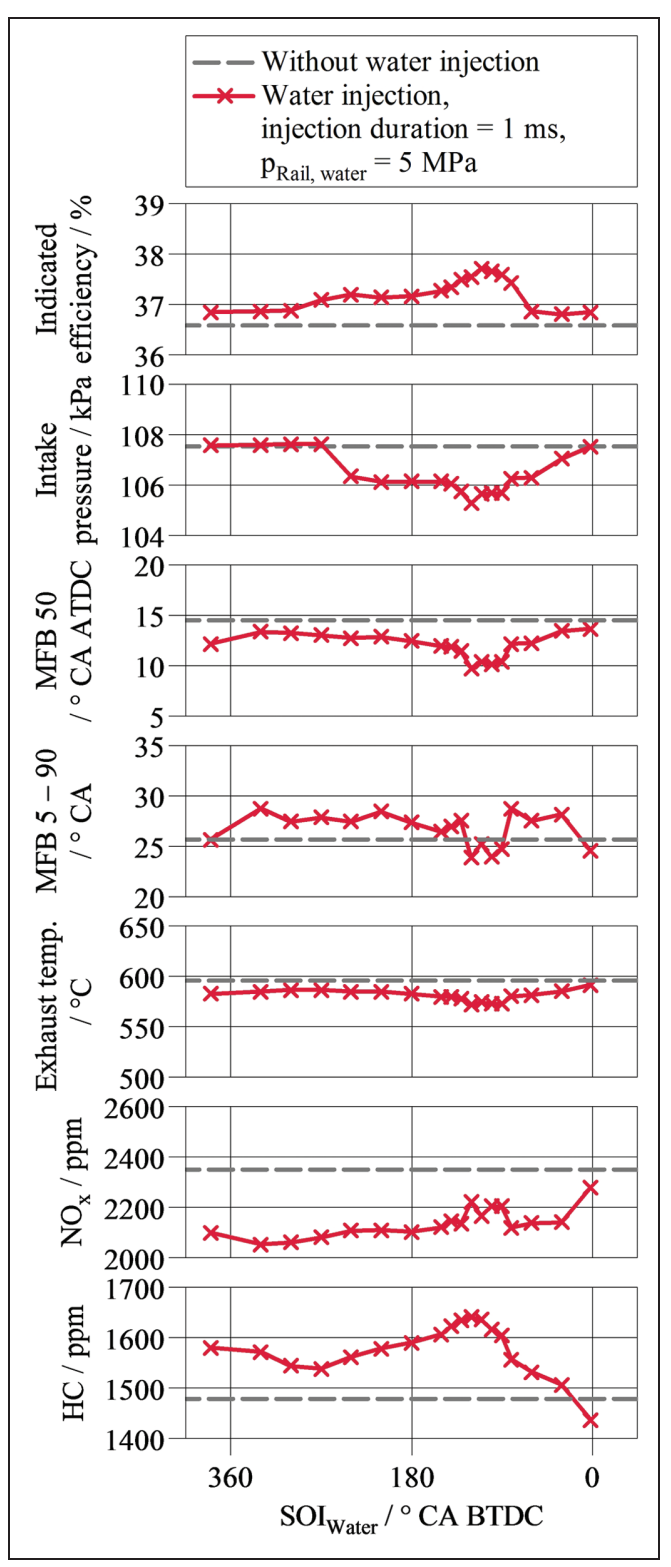

Figure 6. Influence of the start of the water injection on stoichiometric combustion at $\mathrm{n}=2000 \mathrm{I} / \mathrm{min}$ and IMEP = $1.05 \mathrm{MPa}$.

\section{Discussion of test results}

After the theoretical assessment, first tests were conducted in order to determine the ideal timing and pressure for the water injection. A load point of indicated mean effective pressure $($ IMEP) $=1.05 \mathrm{MPa}$ at an engine speed of $n=20001 / \mathrm{min}$ was chosen, because this load point still allows for an operation without cooled external EGR and thus reduces potential cross influences of water and EGR; both acted as an additional diluter. Fuel was injected via the central injector and water via the side injector. The results of the start of water injection variation at this operation point are depicted in Figure 6.

The spark timing was set according to an optimal value of the point of $50 \%$ mass fraction burned (MFB
50) of $7^{\circ}-8^{\circ}$ CA ATDC in case there was no knock restriction for all the following investigations.

An optimum in knock mitigation due to a maximized cooling effect on the cylinder charge was found when the water is injected around the closing of the intake valve; see Table 2. At a start of injection (SOI) of $120^{\circ} \mathrm{CA}$ before top dead centre (BTDC), MFB 50 can be advanced by nearly $5^{\circ} \mathrm{CA}$. This results in an efficiency increase of approximately $3 \%$ and a temperature reduction in the exhaust gas by $24^{\circ} \mathrm{C}$ in maximum. Nitrogen oxide $\left(\mathrm{NO}_{\mathrm{x}}\right)$ emissions can be reduced by up to $13 \%$ for early starts of injection and $5.6 \%$ at an SOI of $120^{\circ} \mathrm{CA}$ BTDC. The hydrocarbon (HC) emissions increase up to $11 \%$ due to the occurrence of more quenching, which is a result of the additional dilution of the cylinder charge and the reduction in combustion temperature.

Since a low pressure level in the water injection system would be cost-efficient, a pressure variation was conducted in the same operation point in order to experimentally determine the influence of the water pressure on the benefits of the concept. Figure 7 depicts the results of this variation, which was conducted at the optimized SOI of $120^{\circ}$ CA BTDC and an injection quantity of $5.3 \mathrm{mg}$, corresponding to $1 \mathrm{~ms}$ injection duration at a water pressure of $10 \mathrm{MPa}$. A clear correlation between MFB 50 and the water pressure can be derived such that lower water pressures result in worse MFB 50. The shallower gradient between 10 and $15 \mathrm{MPa}$ results from the fact that the MFB 50 is already nearly optimal at $10 \mathrm{MPa}$. Thus, no significant improvements remain possible with higher pressure. In addition to the previously described worsening of the primary breakup with lower injection pressures, the reason for this behaviour is expected to be the time span, which is required for injection and evaporation. This time span worsens with lower pressure, and consequently the end gas temperature and knock propensity are not reduced as well as with high pressure levels. Therefore, the efficiency is reduced by $1.1 \%$ at a water pressure level of $2.5 \mathrm{MPa}$ compared to a water pressure level of $10 \mathrm{MPa}$.

In the following, a water pressure of $10 \mathrm{MPA}$ and a start of the water injection of $120^{\circ} \mathrm{CA}$ BTDC were chosen to determine the potential of the condensate injection concept in combination with Miller cycle and cooled external EGR. The load was increased to $\mathrm{IMEP}=1.46 \mathrm{MPa}$ at $\mathrm{n}=30001 / \mathrm{min}$ and the EGR rate was pre-optimized to $16 \%$ (see Figure 8 ).

The engine remained knock limited despite the utilization of both cooled EGR and water injection, due to the high geometric compression ratio of 13.5. In case of stoichiometric combustion with cooled EGR, MFB 50 decreased linearly with increased water quantity and reaches the optimum of $\sim 8^{\circ} \mathrm{CA}$ ATDC at a water-fuel ratio of 50\% (see Figure 8). HC emissions also increased linearly with the water quantity. Consequently, the best fuel consumption was achieved at a water-fuel ratio of $50 \%$ with an efficiency gain of $3.3 \%$. For a lower engine 


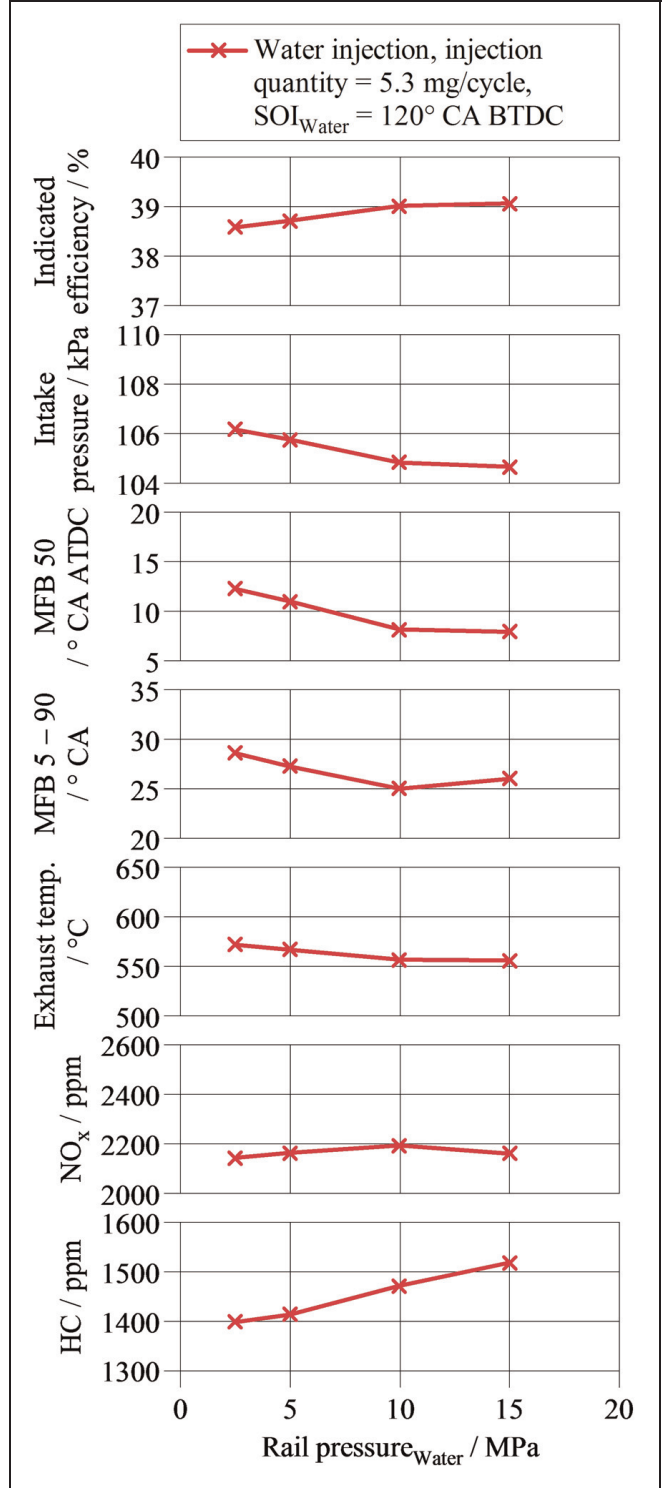

Figure 7. Influence of the water pressure on stoichiometric combustion at $n=2000 \mathrm{I} / \mathrm{min}$ and IMEP $=1.05 \mathrm{MPa}$.

speed of $20001 / \mathrm{min}$, an increase in the efficiency of 3.8\% was achieved when water injection was used in addition to cooled EGR and Miller cycle.

As depicted in Figure 8, the $\mathrm{NO}_{\mathrm{x}}$ emissions remain nearly constant, despite the cooling effect of the water injection, which is due to the improvement in MFB 50 phasing. Also, the burn duration from 5\% to $90 \%$ mass fraction burned (MFB 5 - 90) can be kept constant. The effect of worsened burn duration is compensated by the improvements in MFB 50 such that the burn duration (MFB 5-90) remains nearly constant throughout the variation. The increasing amount of water injection and the achieved improvements in MFB 50 phasing result in a reduction in the exhaust gas temperature by $\sim 60{ }^{\circ} \mathrm{C}$, when comparing no water injection with a water-fuel ratio of $50 \%$. Naturally, such a reduction in temperature will impact the

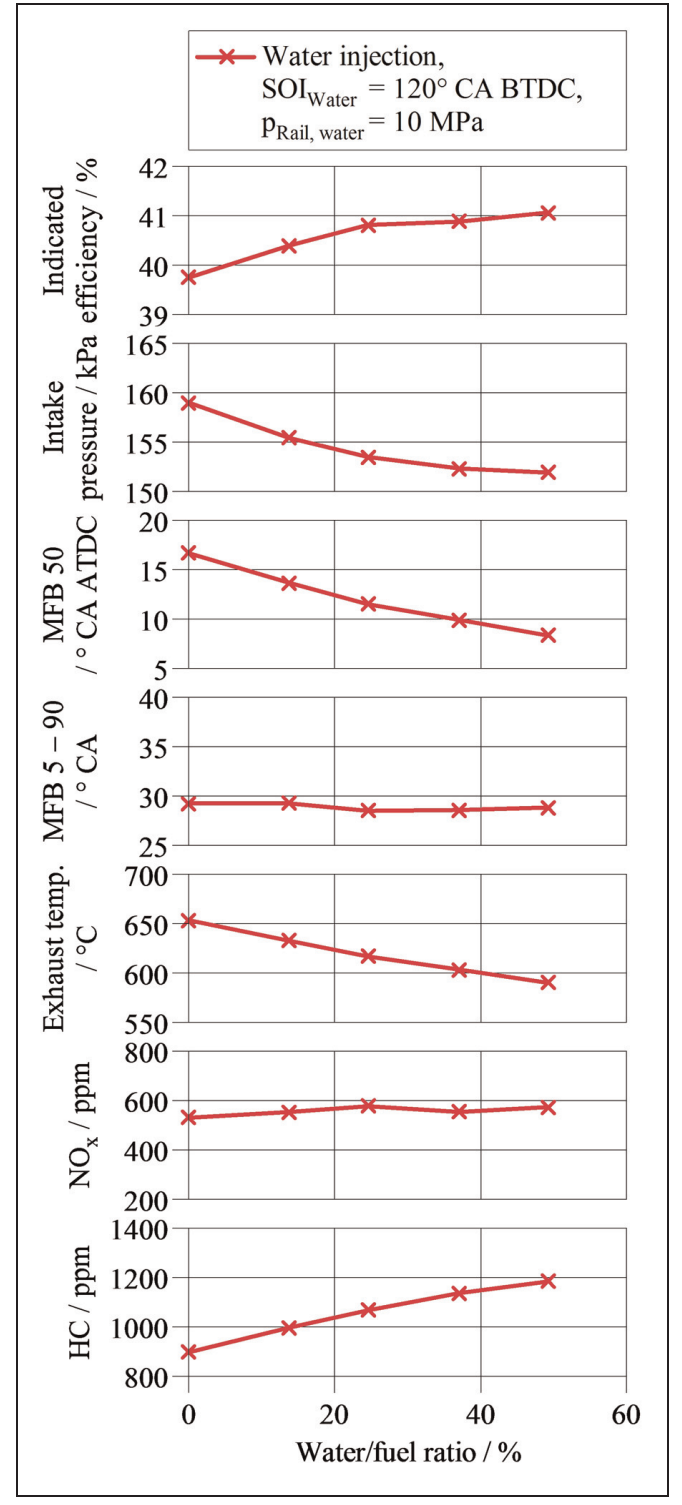

Figure 8. Influence of the injected water quantity on stoichiometric combustion with cooled external EGR (16\%) at $\mathrm{n}=3000 \mathrm{I} / \mathrm{min}$ and IMEP $=1.46 \mathrm{MPa}$.

boosting system layout. This is especially in addition to the temperature reduction, which has already been caused by the efficiency improvements resulting from Miller cycle and cooled EGR.

In Figure 9, the burn function and the fraction of losses of the discussed load point from Figure 8 are depicted without water injection and for the maximum water/fuel ratio of $50 \%$. Both the burn function and the fraction of losses are derived via three-pressure analysis (TPA) in the one-dimensional (1D)-Simulation-Tool GT-Power. Figure 9 shows that the earlier MFB 50 with water injection occurs with a reduced peak burn rate, which results in increased $\mathrm{HC}$ emissions. Regarding the losses, compared to the fuel-air cycle, one can see that the efficiency gain with water injection is dominated by the reduction in losses due to MFB 


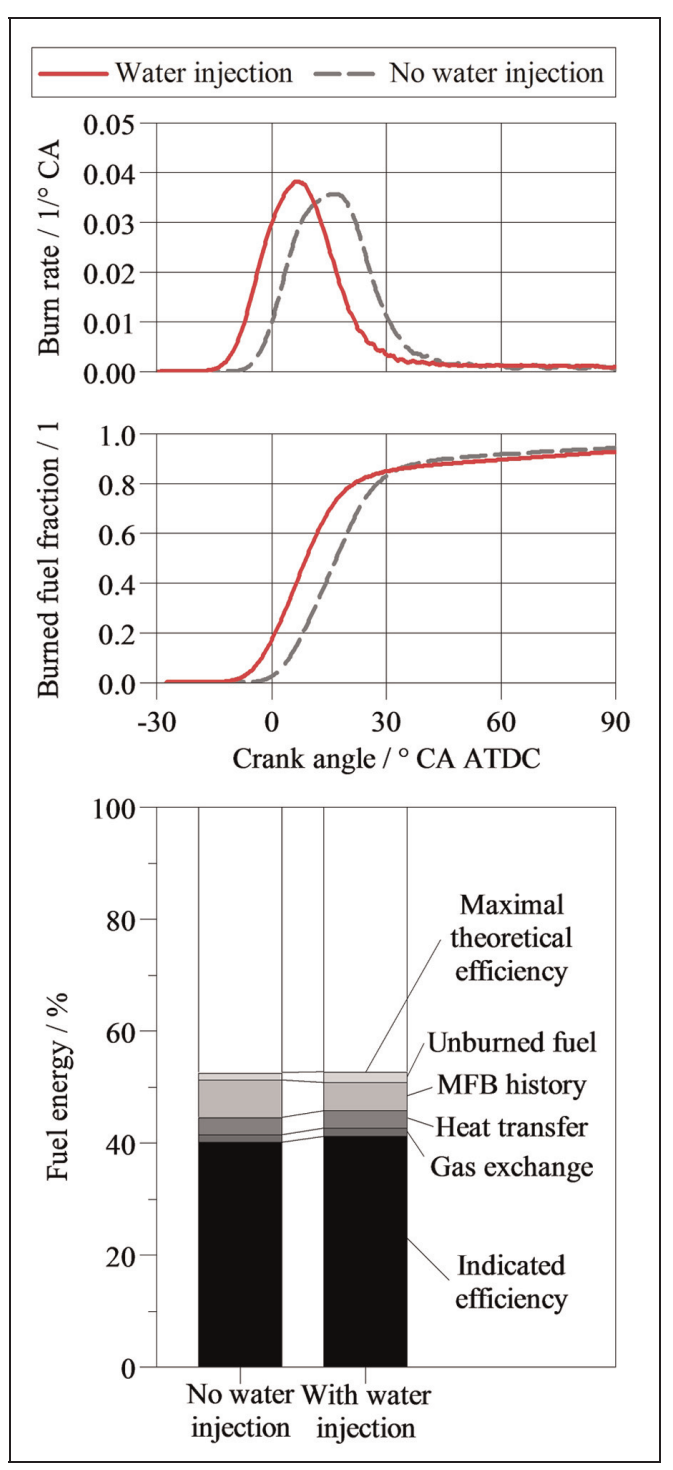

Figure 9. Influence of water injection on burn function and fraction of losses at stoichiometric combustion with cooled external EGR (I6\%) at $\mathrm{n}=3000 \mathrm{I} / \mathrm{min}$ and IMEP $=1.46 \mathrm{MPa}$.

history. The lower heat losses compensate the increased losses due to unburned fuel.

If water injection is applied at load points that are more prone to knocking combustion, the efficiency gain can be increased. An engine speed of $20001 / \mathrm{min}$ and an IMEP of $2.26 \mathrm{MPa}$ were chosen for the variation in the injected water quantity presented in Figure 10. Despite the high compression ratio, the specific load was increased to a level which is typical for today's engines and may be above the level that can expected for future spark ignition (SI) engines with high compression ratio, Miller cycle and external cooled EGR. Thus, a stable operation without water injection was not possible at this load point. To evaluate the potential of the water injection, the curves were extended by second-order polynomial extrapolation. The declared values of the relative improvements of the water injections refer to the extrapolated load point without water injection.

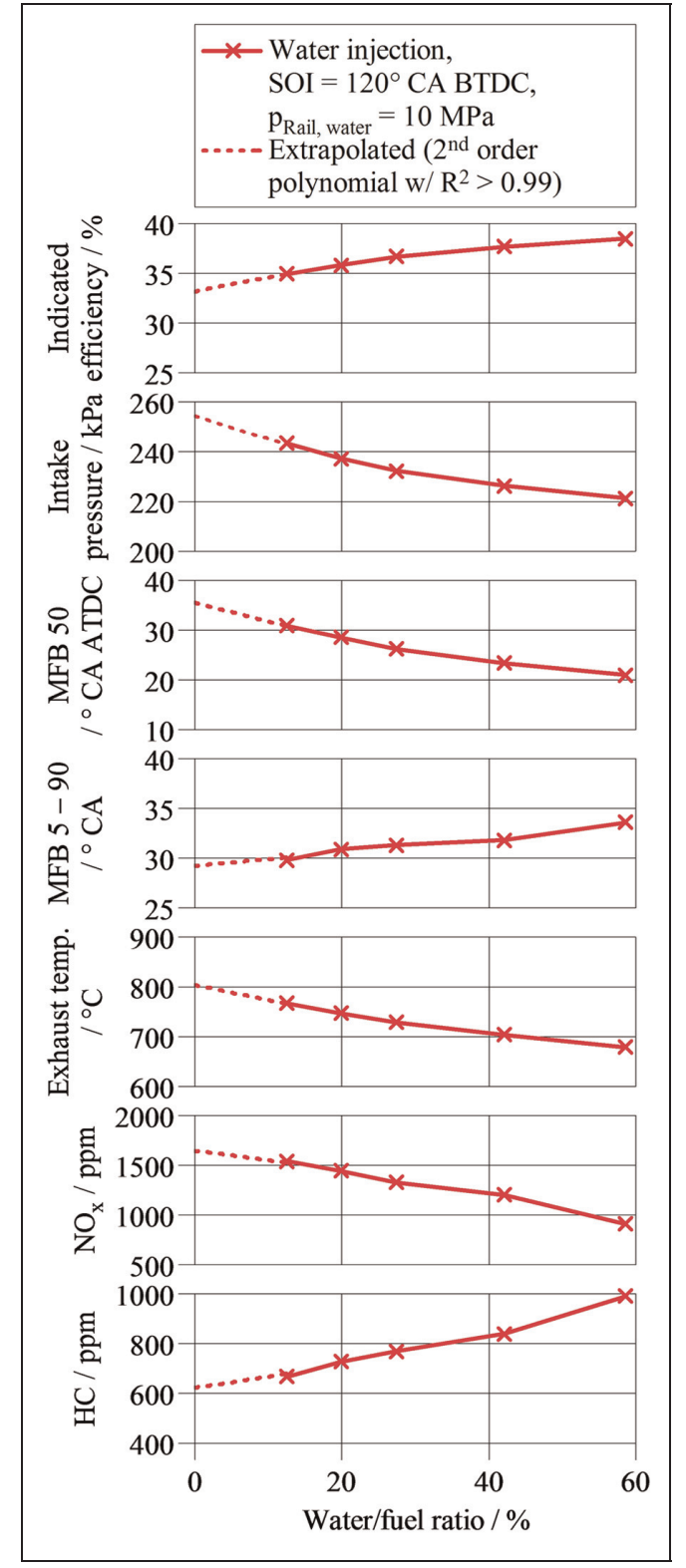

Figure 10. Influence of the injected water quantity on stoichiometric combustion with cooled external EGR at $\mathrm{n}=2000 \mathrm{I} / \mathrm{min}$ and IMEP $=2.26 \mathrm{MPa} \cdot \mathrm{R}^{2}$ : coefficient of determination.

At a water/fuel ratio of $60 \%$, the MFB 50 could be advanced by $\sim 15^{\circ} \mathrm{CA}$. This results in a decrease in the exhaust gas temperature of more than $100{ }^{\circ} \mathrm{C}$ and up to $16 \%$ gain in efficiency. The increase in the burn duration shows that the dilution of the mixture with water cannot be compensated by the earlier MFB 50 contrary to the previous load point (see Figure 8). At the same time, a decrease in the $\mathrm{NO}_{\mathrm{x}}$ emissions of more than $40 \%$ takes place while the increase in the $\mathrm{HC}$ emissions is comparable.

Further fuel consumption reductions can principally be realized with lean burn instead of cooled EGR. In such a case, condensate injection can enable direct fuel consumption reduction via knock mitigation and 


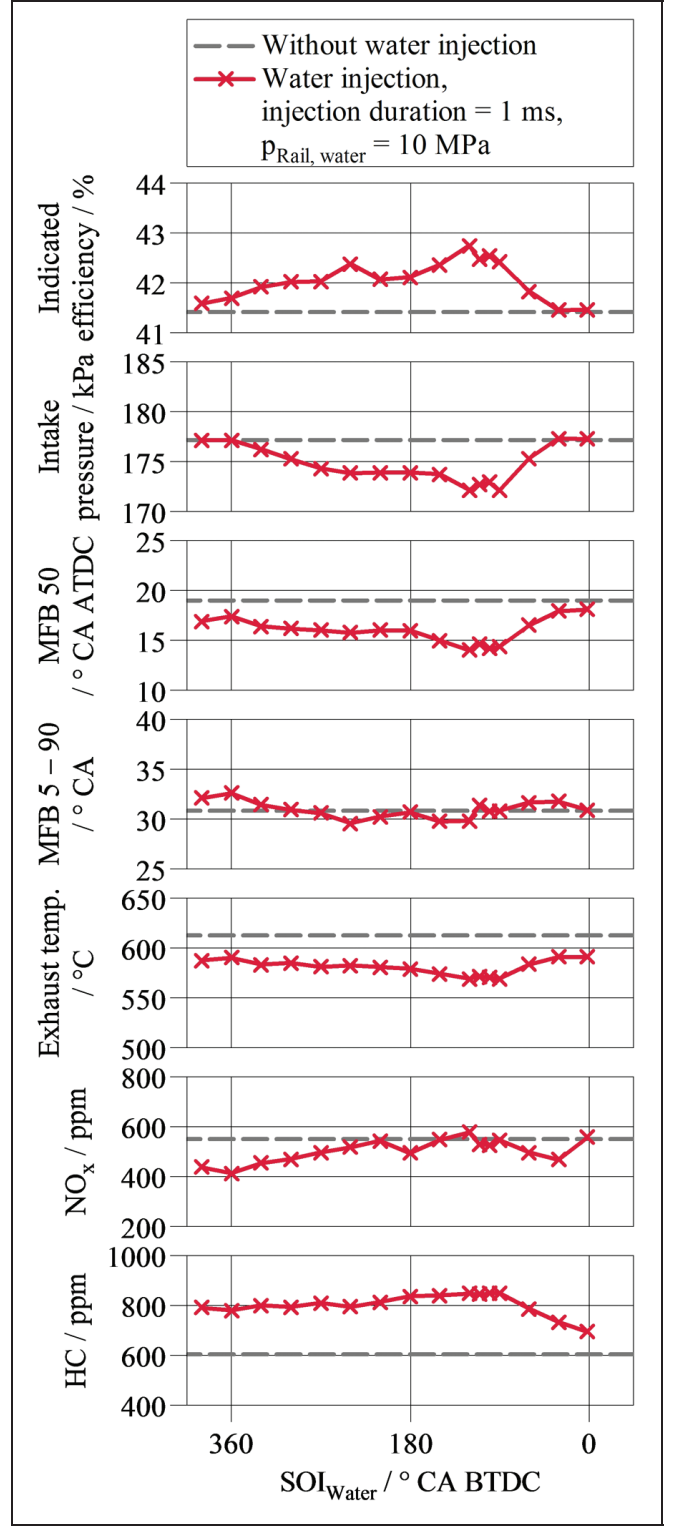

Figure I I. Influence of the start of the water injection on lean combustion at $\mathrm{n}=3000 \mathrm{I} / \mathrm{min}$ and IMEP $=1.46 \mathrm{MPa}$ at $\lambda=1.4$.

indirect fuel consumption reduction by lowering $\mathrm{NO}_{\mathrm{x}}$ raw emissions in the case of an exhaust aftertreatment via $\mathrm{NO}_{\mathrm{x}}$ storage catalysts. If selective catalytic reduction (SCR) is used, then the total cost of ownership can be reduced by less dosing agent which is required if the $\mathrm{NO}_{\mathrm{x}}$ engine-out emissions can be reduced. In such a scenario, the start of the water injection might be balanced between direct fuel consumption reduction and a reduction in $\mathrm{NO}_{\mathrm{x}}$ emissions. In Figure 11, an SOI variation at an engine speed of $\mathrm{n}=30001 / \mathrm{min}$, IMEP $=1.46 \mathrm{MPa}$ and an air/fuel ratio of $\lambda=1.4$ is presented. A water injection quantity corresponding to a water/fuel ratio of $\sim 26 \%$ was chosen. Again, best knock mitigation is achieved at a late SOI at the closing of the intake valve. Preponing the SOI results in a

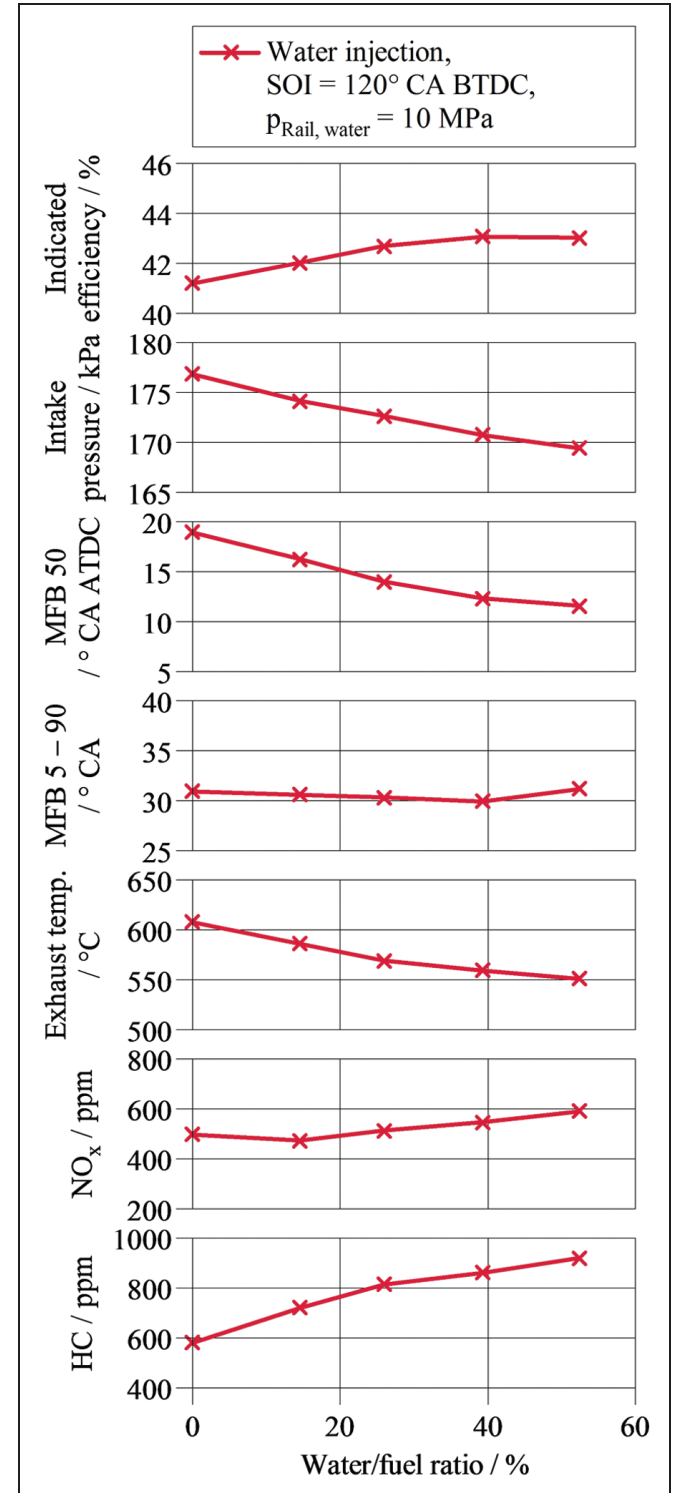

Figure I2. Influence of the injected water quantity on lean combustion at $\mathrm{n}=3000 \mathrm{I} / \mathrm{min}$ and IMEP $=1.46 \mathrm{MPa}$ at $\lambda=1.4$.

trade-off between the reduced fuel consumption advantages and the reduced $\mathrm{NO}_{\mathrm{x}}$ emissions.

For the following investigation on the water injection quantity at lean combustion, a load point of $\mathrm{n}=30001 / \mathrm{min}, \quad$ IMEP $=1.46 \mathrm{MPa}$ and an air/fuel ratio of $\lambda=1.4$ were chosen again. Also, the SOI for water of $120^{\circ} \mathrm{CA}$ BTDC and the injection pressure of $10 \mathrm{MPa}$ were kept constant to the previous investigations with cooled EGR.

Similar results are achieved if the engine is operated at lean combustion instead of cooled EGR. The results depicted in Figure 12 show the same trend in emissions when increasing the amount of water injected into the combustion chamber. The maximum gain in efficiency is $4.5 \%$ at a water/fuel ratio of $40 \%$. The corresponding exhaust gas temperature reduction is $50{ }^{\circ} \mathrm{C}$. The burn duration remains nearly constant throughout the 


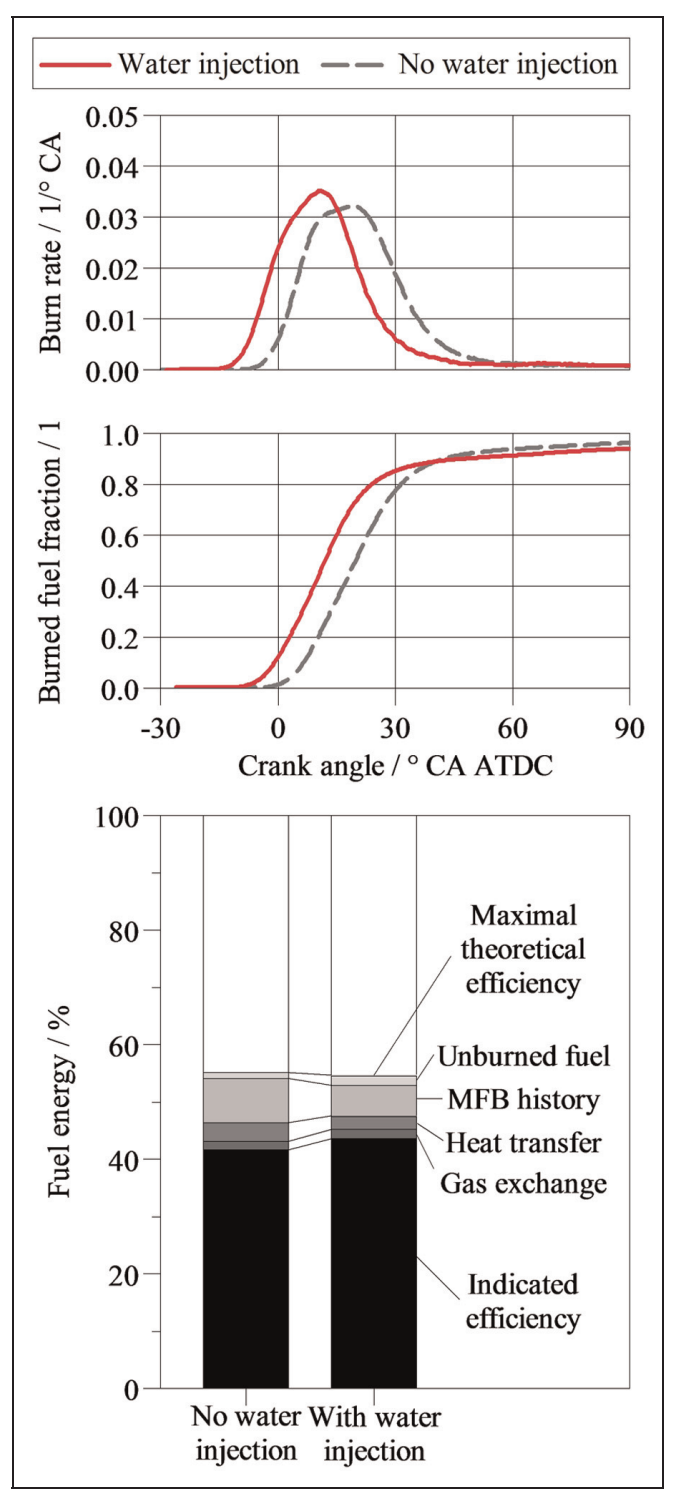

Figure 13. Influence of water injection on burn function and fraction of losses at lean combustion at $\mathrm{n}=3000 \mathrm{I} / \mathrm{min}$ and IMEP $=1.46 \mathrm{MPa}$ at $\lambda=1.4$.

variation. However, at lean combustion, a retarded MFB 50 and longer burn duration (MFB 5-90) are present (see also Figure 13). At the same time, a higher conversion rate and thus lower $\mathrm{HC}$ emissions can be found. The higher inert gas share in case of lean combustion results in lower exhaust gas temperatures and heat losses. ${ }^{36,37}$ In this load point, the lower heat losses and losses that are due to unburned fuel overcompensate the retarded MFB 50 and longer burn duration (MFB 5-90). This enables a higher efficiency for lean combustion with water injection compared to stoichiometric combustion with cooled EGR and water injection.

\section{Conclusion}

The object of this study was to explore the potential of water injection to reduce knock sensitivity and improve efficiency in DI gasoline engines.
Exhaust heat recovery was assumed as a potential future technology to improve engine efficiency by up to $3 \%-5 \%$, while offering new potentials for the combustion system. Exhaust condensate can become available to realize an engine concept with dual DI. The additionally injected condensate can be fully recycled if the exhaust gas can be cooled down to its dew point, resulting purely from the water out of the combustion of the fuel itself. The loss in water from the $100 \%$ humid exhaust gases leaving the tailpipe is compensated by the water which is formed during the combustion of the fuel. This allows a high degree of flexibility in the amount of condensate that can be injected.

Combustion system investigations regarding the potential benefits of this concept were carried out on a single-cylinder engine. DI was considered for the condensate as well as for the gasoline injection. The proposed condensed water injection concept enabled an increase in the thermal efficiency by $\sim 3.3 \%-3.8 \%$ in the region of the minimum brake-specific fuel consumption (BSFC). A much higher efficiency gain of up to $16 \%$ is possible at full-load operation. This is, if condensate injection is used in addition to Miller cycle and cooled external EGR. Moreover, at Miller cycle and lean burn operation, the condensate injection allows efficiency improvements of up to $4.5 \%$ also in the region of the minimum BSFC.

Condensate injection and Miller cycle are sufficient to enable optimal combustion at medium part load up to $\sim 1.0 \mathrm{MPa}$ brake mean effective pressure (BMEP) even with compression ratio 13.5. In such operation points, the condensate injection would allow to eliminate the necessity of cooled external EGR for a fast reaction during transients. The combination of Miller cycle and cooled EGR with condensate injection will allow a further increased efficiency also at part load for an engine concept with variable compression ratio since a higher compression ratio can be used for higher loads. In this combination, the part load compression ratio could be chosen significantly higher than a compression ratio of 13.5 .

Improvements of ignition systems could support the condensate injection concept even further by supporting a fast and safe ignition of the cylinder charge, which is not only diluted by EGR but also by the additional water. Moreover, material compatibility issues of the water injection system components and other aspects, such as freezing protection, have to be addressed in further development stages of the extended direct condensate injection system.

\section{Declaration of conflicting interests}

The author(s) declared no potential conflicts of interest with respect to the research, authorship, and/or publication of this article.

\section{Funding}

The author(s) received no financial support for the research, authorship, and/or publication of this article. 


\section{References}

1. NN. Regulation (EC) No 443/2009 of the European Parliament and of the Council setting emission performance standards for new passenger cars as part of the Community's integrated approach to reduce $\mathrm{CO}_{2}$ emissions from light-duty vehicles, Bruxelles, 2009.

2. NN. Proposal for a Regulation of the European Parliament and of the Council amending Regulation (EC) No $443 / 2009$ to define the modalities for reaching the 2020 target to reduce $\mathrm{CO}_{2}$ emissions from new passenger cars, Bruxelles, 2012.

3. NN. Energy Independence and Security Act of 2007, H.R.6.ENR.

4. NN. 2017 and Later Model Year Light-Duty Vehicle Greenhouse Gas Emissions and Corporate Average Fuel Economy Standards, Federal Register, Vol. 77, No. 199, 2012.

5. Hofmann P, Kieberger M, Geringer B, Willand $\mathbf{J}$ and Jelitto C. Release mechanisms and influencing variables on preignition phenomena of highly boosted SI engines. In: Proceedings of the 17th Aachen colloquium automobile and engine technology, Aachen, Germany, 6-8 October 2008.

6. Cairns A, Fraser N and Blaxill H. Pre versus post compressor supply of cooled EGR for full load fuel economy in TC gasoline engines. SAE technical paper 2008-010425, 2008. DOI: 10.4271/2008-01-0425.

7. Grandin B, Angström H, Stalhammer P and Olofsson E. Knock suppression in a TC SI engine by using cooled EGR. SAE technical paper 982476, 1998. DOI: 10.4271/ 982476.

8. Grandin B and Angström H. Replacing fuel enrichment in a TC SI engine: lean burn or cooled EGR. SAE technical paper 1999-01-3505, 1999. DOI: 10.4271/1999-013505 .

9. Thewes M, Baumgarten H, Dohmen J, Uhlmann T, Seibel J, Balazs A, et al. Gasoline combustion systems beyond 2020. In: Proceedings of the 23rd Aachen colloquium automobile and engine technology, Aachen, Germany, 6-8 October 2014.

10. Kadunic S, Baar R, Scherer F, Zegenhagen T and Ziegler F. Heat2Cool-engine operation at charge air cooling below ambient temperature. In: Proceedings of the 22nd Aachen colloquium automobile and engine technology, Aachen, Germany, 7-9 October 2013.

11. Liebl J, Neugebauer S, Eder A, Mazar B and Stütz W. The thermoelectric generator from BMW is making use of waste heat. MTZ Worldw 2009; 70(4): 4-11.

12. Freymann R, Strobl W and Obieglo A. The turbosteamer: a system introducing the principle of cogeneration in automotive applications. MTZ Worldw 2008; 69(5): 20-27.

13. Smague $P$ and Leduc $P$. Integrated waste heat recovery system with Rankine cycle. In: Proceedings of the 22nd Aachen colloquium automobile and engine technology, Aachen, Germany, 7-9 October 2013.

14. Eaton D. Cruising economy by use of water injection. SAE technical paper 460198, 1946. DOI: $10.4271 / 460198$.

15. Rowe $M$ and Ladd $G$. Water injection for aircraft engines. SAE technical paper 460192, 1946. DOI: $10.4271 / 460192$.

16. Nicholls J, EI-Messiri I and Newhali H. Inlet manifold water injection for control of NOx - theory and experiment. SAE technical paper 690018, 1969. DOI: $10.4271 / 690018$.

17. Lestz S, Meyer W and Colony C. Emissions from a direct-cylinder water-injected spark-ignition engine. SAE technical paper 720113, 1970. DOI: 10.4271/720113.

18. Modak A and Caretto L. Engine cooling by direct injection of cooling water. SAE technical paper 700887, 1970. DOI: $10.4271 / 700887$.

19. Weatherford W and Quillian R. Total cooling of piston engines by direct water injection. SAE technical paper 700886, 1970. DOI: 10.4271/700886.

20. Peters B and Stebar R. Water-gasoline fuels - their effect on spark ignition engine emissions and performance. SAE technical paper 760547, 1976. DOI: $10.4271 / 760547$.

21. Harrington J. Water addition to gasoline - effect on combustion, emissions, performance and knock. SAE technical paper 820314, 1982. DOI: 10.4271/820314.

22. Lanzafame R. Water injection effects in a single-cylinder CFR engine. SAE technical paper 1999-01-0568, 1999. DOI: 10.4271/1999-01-0568.

23. Brusca S and Lanzafame R. Water injection in IC-SI engines to control detonation and to reduce pollutant emissions. SAE technical paper 2003-01-1912, 2003. DOI: 10.4271/2003-01-1912.

24. Yaws CL. Thermophysical properties of chemicals and hydrocarbons. Norwich, NY: William Andrew Inc., 2008.

25. Thewes M, Müther M, Pischinger S, Budde M, Brunn A, Sehr A, et al. Analysis of the impact of 2-methylfuran on mixture formation and combustion in a direct-injection spark-ignition engine. Energ Fuel 2011; 25(12): 55495561. DOI: 10.1021/ef201021a.

26. Heywood JB. Internal combustion engine fundamentals. New York: McGraw-Hill Inc., 1988.

27. Scott DW. Chemical thermodynamic properties of hydrocarbons and related substances: properties of the alkane hydrocarbons, $\mathrm{Cl}$ through $\mathrm{C10}$ in the ideal gas state from 0 to $1500 \mathrm{~K}$. US Bureau of Mines, Bulletin 666, 1974. (in NIST Chemistry WebBook. Gaithersburg, MD: National Institute of Standards and Technology (NIST)), http:// webbook.nist.gov (2010, accessed 9 April 2015).

28. Scott DW. Correlation of the chemical thermodynamic properties of alkane hydrocarbons. J Chem Phys 1974; 60: 3144-3165 (in NIST Chemistry WebBook. Gaithersburg, MD: National Institute of Standards and Technology (NIST)), http://webbook.nist.gov (2010, accessed 9 April 2015).

29. Chase MW. NIST-JANAF thermo-chemical tables. 4th ed. J Phys Chem Ref Data, Monograph 9, 1998; 1-1951. (in NIST Chemistry WebBook. Gaithersburg, MD: National Institute of Standards and Technology (NIST)), http://webbook.nist.gov (2010, accessed 9 April 2015).

30. Von Ohnesorge W. Die Bildung von Tropfen an Düsen und die Auflösung flüssiger Strahlen. Zamm: Z Angew Math Me 1936; 16(6): 355-358.

31. Baumgarten C. Mixture formation in internal combustion engines. Berlin, Heidelberg: Springer-Verlag, 2006.

32. Thewes M. Potentiale aktueller und zukünftiger Biokraftstoffe für ottomotorische Brennverfahren, Dissertation, Institute for Combustion Engines, RWTH Aachen University, Aachen, 2014.

33. Yaws CL. Transport properties of chemicals and hydrocarbons. Norwich, NY: William Andrew Inc., 2009. 
34. Kestin J, Sokolov M and Wakeham WA. Viscosity of liquid water in the range $-8{ }^{\circ} \mathrm{C}$ to $150{ }^{\circ} \mathrm{C}$. $J$ Phys Chem Ref Data 1978; 7(3): 941-948.

35. Thewes M, Müther M, Brassat A, Pischinger S and Sehr A. Analysis of the effect of bio-fuels on the combustion in a downsized DI SI engine. SAE Int J Fuels Lubr 2012; 5(1): 274-288. DOI: 10.4271/2011-01-1991.

36. Lumsden G, Eddleston D and Sykes R. Comparing lean burn and EGR. SAE technical paper 970505, 1997. DOI: 10.4271/970505.

37. Südhaus N. Möglichkeiten und Grenzen der Inertgassteuerung für Ottomotoren mit variablen Ventilsteuerzeiten. Dissertation, RWTH Aachen University, Aachen, 1988.

\section{Appendix I}

\section{Notation}

$\mathrm{c}_{\mathrm{p}} \quad$ specific heat capacity

d characteristic length

$\Delta \mathrm{h}_{\mathrm{v}} \quad$ enthalpy of vaporization

$\mathrm{v} \quad$ velocity of the fluid relative to ambient conditions

dynamic viscosity of the fluid relative air/fuel ratio density of the fluid surface tension of the fluid 